\title{
Prevalence of obesity and overweight and associated nutritional factors in a population-based Swiss sample: an opportunity to analyze the impact of three different European cultural roots
}

\author{
Adam Ogna $\cdot$ Valentina Forni Ogna $\cdot$ \\ Murielle Bochud · Fred Paccaud · Luca Gabutti • \\ Michel Burnier
}

Received: 29 July 2013/ Accepted: 17 December 2013/Published online: 28 December 2013

(C) Springer-Verlag Berlin Heidelberg 2013

\begin{abstract}
Purpose Obesity represents a growing public health concern worldwide. The latest data in Switzerland rely on self-reported body mass index (BMI), leading to underestimation of prevalence. We reassessed the prevalence of obesity and overweight in a sample of the Swiss population using measured BMI and waist circumference (WC) and explored the association with nutritional factors and living in different linguistic-cultural regions.

Methods Data of 1,505 participants of a cross-sectional population-based survey in the three linguistic regions of Switzerland were analyzed. BMI and WC were measured, and a 24-h urine collection was performed to evaluate dietary sodium, potassium and protein intake.

Results The prevalence of overweight, obesity and abdominal obesity was $32.2,14.2$ and $33.6 \%$, respectively.
\end{abstract}

On behalf of the Swiss Survey on Salt Group.

Conen D. (Basel), Hayoz D. (Fribourg), Guessous I. (Genève), Péchère-Bertschi A. (Genève), Erne P. (Luzern), Binet I. (St-Gallen), Muggli F. (Ticino), Gallino A. (Ticino), Meier P. (Valais) and Suter P.M. (Zürich) are the Swiss Survey on Salt Group members.

Adam Ogna and Valentina Forni Ogna are joint first authors.

A. Ogna $(\bowtie) \cdot$ L. Gabutti

Department of Internal Medicine and Nephrology, Locarno

Hospital, Locarno, Switzerland

e-mail: adam.ogna@chuv.ch

V. Forni Ogna $\cdot$ M. Burnier

Service of Nephrology and Hypertension, Lausanne University

Hospitals, Lausanne, Switzerland

M. Bochud · F. Paccaud

Community Prevention Unit, University Institute of Social and

Preventive Medicine (IUMSP), Lausanne, Switzerland
Significant differences were observed in the regional distribution, with a lower prevalence in the Italian-speaking population. Low educational level, current smoking, scarce physical activity and being migrant were associated with an higher prevalence of obesity. Sodium, potassium and protein intake increased significantly across BMI categories. Conclusions Obesity and overweight affect almost half of the Swiss adolescents and adults, and the prevalence appears to increase. Using BMI and WC to define obesity led to different prevalences. Differences were furthermore observed across Swiss linguistic-cultural regions, despite a common socio-economic and governmental framework. We found a positive association between obesity and salt intake, with a potential deleterious synergistic effect on cardiovascular risk.

Keywords Obesity - Overweight · Abdominal obesity · Nutrition assessment $\cdot$ Cultural root $\cdot$ Salt intake

\section{Introduction}

The association between obesity and increased health risk is well established to date. Obesity has been related to increased risk of hypertension, diabetes, cardiovascular events, several cancers and mortality [1-5]. The prevalence of obesity is increasing worldwide and is becoming a growing public health concern $[6,7]$.

According to data of the World Health Organization (WHO), the prevalence of obesity differs across European countries [8]. Switzerland is composed of three main linguistic regions: a German-, a French- and an Italianspeaking area. It therefore represents a unique opportunity to study the difference across three groups with different cultural roots, living in a single nation and thus having a common socio-economic and governmental framework. 
Previous data about obesity prevalence in Switzerland were collected in the Swiss Health Surveys (SHS). The last survey (2007) was based on the telephonic interview of nearly 19,000 subjects, recording self-reported height and weight [9]. Self-reported anthropometric measures are known to result in an underestimation of body mass index (BMI), as a consequence of an overestimation of body height and an underestimation of weight [10, 11]. A comparison between studies based on measured anthropometric parameters (five studies, 1981-2002) and others relying on self-reported height and weight (five studies, 1977-2003) confirmed a significant underestimation of BMI in the firsts. The mean BMI was $1 \mathrm{~kg} / \mathrm{m}^{2}$ lower when self-reported, resulting in the misclassification of $60 \%$ of obese people when compared to measured BMI [12].

The use of waist circumference (WC) to define obesity may identify a slightly different population than a definition based on BMI; furthermore, cardiovascular risk was found to be increased in subjects with normal BMI and increased WC $[4,13]$. To our knowledge, there are to date no data on the prevalence of abdominal obesity in the Swiss population.

It has been recently postulated that salt intake may play a causal role in the development of obesity [14, 15]. This is known as the "salted food addiction hypothesis," which postulates that salt is an important factor in food seeking behaviors via mild opiate agonist properties [16]. Although it is generally acknowledged that obese people eat more salt than lean people, there are limited population-based data linking BMI with salt intake estimated from 24-h urine collections.

In this analysis, we used data from the Swiss Survey on Salt, a large population-based survey including subjects from the three linguistic area of Switzerland, to assess the prevalence and distribution of measured overweight and obesity, as well as their associated factors. We also explored nutritional factors associated with overweight and obesity, using objective biomarkers from a 24-h urine collection including urinary sodium excretion as a proxy for dietary salt intake.

\section{Methods and procedures}

\section{Sampling strategy}

The Swiss Survey on Salt was promoted by the Swiss Federal Office of Public Health (BAG) within the context of the national program on Nutrition and Movement. It aimed primarily at estimating dietary salt intake and hypertension prevalence in people aged 15 years or more who are permanent residents in Switzerland.
Recruitment took place from January 2010 to March 2012 and was based on a two-level sampling strategy similar to the one used for Swiss Health National Surveys [9]. Households were randomly selected by the Swiss Federal Statistical Office, based on the Swiss fixed-line phone directory, which groups all landline phone connections in Switzerland and is regularly updated by the major Swiss phone provider. In a first step, we contacted these households by sending an information letter followed by phone calls with a maximum of three attempts on different days. In a second step, we randomly selected, during the phone call, one person from the household to take part to the study, using a computer-generated random number. We recruited participants in eight predefined sex- and agestrata (men and women aged 15-29, 30-44, 45-59 and $\geq 60$ years). Because of difficulties to recruit young and middle-aged people, limited convenience sampling (primary via leaflets targeting secondary, professional schools or universities) was conducted in selected centers. No monetary incentive was offered to motivate survey participation. Participants received $20 \mathrm{CHF}$ (15€) as compensation of travel expenses. Overall, participation rate was $10 \%$.

\section{Clinical data}

The participating subjects were evaluated in one of the 11 participating study centers on two consecutive days. Weight was measured in light indoor clothing without shoes, to the nearest $100 \mathrm{~g}$ using a medical scale, and height was measured to the nearest centimeter using a wallmounted stadiometer. BMI was calculated as weight (in $\mathrm{kg}$ ) divided by height squared (in $\mathrm{m}$ ) and categorized in three groups according to WHO recommendations [7]: normal weight $\left(<25 \mathrm{~kg} / \mathrm{m}^{2}\right)$, overweight $\left(\geq 25\right.$ to $\left.<30 \mathrm{~kg} / \mathrm{m}^{2}\right)$ and obese $\left(\geq 30 \mathrm{~kg} / \mathrm{m}^{2}\right)$.

Waist circumference (WC) was measured to the nearest centimeter with a nonstretchable tape over the unclothed abdomen at the narrowest point between the lowest rib and the iliac crest. Abdominal obesity was defined as WC $\geq 102 \mathrm{~cm}$ for men and $\geq 88 \mathrm{~cm}$ for women, according to the criteria commonly used for the definition of the metabolic syndrome (ATP III criteria: Third Report of the Expert Panel on Detection, Evaluation and Treatment of High Blood Cholesterol in Adults) [17].

Data on medication, smoking status, education level, physical activity and dietary habits (including attention paid to diet) were collected using a questionnaire, administered by trained health professionals during the second visit. For the purpose of the present analyses, only current smokers were considered as smokers. Education was split into three levels (primary, secondary and tertiary). Physical 
activity was considered as present if participants reported to do leisure-time physical activity more than once a week.

Participants were given two 3-1 plastic bottles and standardized instructions on how to collect 24-h urine. Urine volume was adjusted by self-reported collection time (calculated from reported start and end time of the collection). Participants with suspected incomplete urinary collection were excluded from the analysis, i.e., subjects whose urinary volume was $<300 \mathrm{ml} / 24 \mathrm{~h}$ and subjects who reported not having collected all 24-h urine.

\section{Laboratory analysis}

Urine samples were subsequently transported at $-20{ }^{\circ} \mathrm{C}$ to the Central Chemical Laboratory of Lausanne University Hospital (CHUV, Lausanne, Switzerland) for centralized analyses using standard methods and stringent internal quality controls.

Urine sodium (intra- and inter-batch $\mathrm{CV}$ : 0.30 and $0.60 \%$, respectively) and urine potassium (0.40 and $0.90 \%$ ) were measured by indirect potentiometry; urine urea $(1.30$ and $1.90 \%)$ for a concentration around $112 \mathrm{mmol} / \mathrm{l} ; 0.70$ and $1.50 \%$ for a concentration around $291 \mathrm{mmol} / \mathrm{l} ; 0.90$ and $1.30 \%$ for a concentration around $301 \mathrm{mmol} / \mathrm{l}$ ) was measured by urease-GLDH method.

Dietary salt intake was estimated by measured urinary 24-h sodium excretion, using a conversion factor of $0.0584 \mathrm{~g} \mathrm{NaCl}$ per mmol of sodium $(\mathrm{Na})$. Estimated daily protein intake was calculated from the 24-h urea nitrogen (UNA), adding a nonurinary nitrogen excretion rate of $0.031 \mathrm{~g}$ nitrogen $/ \mathrm{kg}$ body weight/day [daily protein inta$\mathrm{ke}=(0.031 \times$ body weight + UNA $) \times 6.25]$, as proposed by Maroni [18]. Using measured urinary sodium and potassium, the urinary $\mathrm{Na}-\mathrm{K}$ ratio was calculated, which has been previously used as a marker of the quality of nutrition $[19,20]$.

\section{Ethics}

The Swiss Survey on Salt complied with the Declaration of Helsinki and was approved by the local Institutional Ethics Committees of each participating center. All participants gave written informed consent. For participants below age 18 years, written consent from one parent or a legal representative was obtained.

\section{Statistical analyses}

Statistical analysis was conducted using Stata 11.0 for Windows (Stata Corp LP, TX, USA).

Mean and SD were used to describe unadjusted continuous variables, and percentages to describe dichotomous or categorical variables. Prevalences were described with proportions by categories of interest. We used $t$ test, ANOVA and $\chi^{2}$ test to compare the characteristics of groups were appropriated, and a nonparametric test by Cuzick to assess trend across ordered groups (nptrend in Stata). We conducted multiple logistic regression in the models with dichotomous dependent variables (obesity, overweight and abdominal obesity), including linguistic region, age, sex, smoking status, educational status and physical activity as covariates. The associations of BMI as continuous dependent variable and the above-mentioned covariates were explored using multiple linear regression. Statistical significance was established for $p<0.05$. We explored whether factors associated with overweight, obesity and abdominal obesity differed across linguistic regions, by adding appropriate interaction terms, one by one, in the models and conducting likelihood ratio tests. Similarly, we explored whether the association of BMI with urinary $\mathrm{Na} / \mathrm{K}$ ratio differed across regions. Given the number of interaction tests conducted (i.e., $>10$ ), we used a $p$ value cut-off of $<0.01$ to declare an interaction as significant.

\section{Results}

Sample characteristics

Overall, 1,550 subjects completed the Swiss Survey on Salt. Forty-five subjects $(2.9 \%)$ were excluded because of missing or incomplete urinary collection (three subjects) and one or more missing variable in questionnaire data (42 subjects), so that 1,505 subjects ( 725 men and 780 women) were considered for the present analysis. A total of 487 subjects lived in the French-speaking part of Switzerland (233 men and 254 women), 811 in the German-speaking (393 men and 418 women) and 207 in the Italian-speaking region (99 men and 108 women). Participants of the Italian region had less often a tertiary educational level than French- or German-speaking participants, and differences were observed in the leisure-time physical activity, with subjects from the Italian-speaking region practicing less often sport than subjects from the German-speaking region. The study population is further described in Table 1 .

Prevalence of overweight and obesity

Body mass index (BMI) was $26.1 \pm 4.3 \mathrm{~kg} / \mathrm{m}^{2}$ in men (mean $\pm \mathrm{SD}$ ) and $24.4 \pm 4.8 \mathrm{~kg} / \mathrm{m}^{2}$ in women, with significant differences in the distribution across the three linguistic regions: mean BMI was similar in subjects from the French- and German-speaking region (25.4 \pm 5.1 and $25.3 \pm 4.4 \mathrm{~kg} / \mathrm{m}^{2}$, respectively) and lower in the Italianspeaking subjects $\left(24.4 \pm 4.3 \mathrm{~kg} / \mathrm{m}^{2}\right)$. Body height was 
Table 1 Characteristics of the study population

\begin{tabular}{|c|c|c|c|c|c|}
\hline$N$ & $\begin{array}{l}\text { All } \\
1,505\end{array}$ & $\begin{array}{l}\text { French } \\
487\end{array}$ & $\begin{array}{l}\text { German } \\
811\end{array}$ & $\begin{array}{l}\text { Italian } \\
207\end{array}$ & $p$ \\
\hline \multicolumn{6}{|l|}{ Age (years) } \\
\hline $\begin{array}{l}\text { Mean } \pm \text { SD } \\
\operatorname{Sex}(\%)\end{array}$ & \multicolumn{4}{|c|}{$\operatorname{Sex}(\%)$} & $0.19 *$ \\
\hline Men & 48.2 & 47.8 & 48.5 & 47.8 & 0.97 \\
\hline \multicolumn{6}{|l|}{ Country of birth (\%) } \\
\hline Switzerland & 78.6 & 75.6 & 78.9 & 84.5 & 0.03 \\
\hline \multicolumn{6}{|l|}{ Educational level (\%) } \\
\hline Primary & 15.6 & 17.2 & 13.7 & 19.3 & 0.02 \\
\hline Secondary & 44.1 & 42.5 & 43.6 & 49.8 & \\
\hline Tertiary & 40.3 & 40.2 & 42.7 & 30.9 & \\
\hline Current smoking & 27.8 & 29.2 & 27.6 & 25.6 & 0.62 \\
\hline \multicolumn{6}{|c|}{ Leisure-time physical activity (\%) } \\
\hline$>1 \times /$ week & 49.1 & 44.6 & 53.6 & 41.9 & 0.001 \\
\hline \multicolumn{6}{|l|}{$B M I\left(k g / m^{2}\right)(\%)$} \\
\hline $\begin{array}{l}\text { Mean } \pm \text { SD } \\
\quad(\min -\max )\end{array}$ & $\begin{array}{l}25.2 \pm 4.7 \\
\quad(15.1-46.3)\end{array}$ & $\begin{array}{l}25.4 \pm 5.1 \\
\quad(15.1-45.8)\end{array}$ & $\begin{array}{c}25.3 \pm 4.4 \\
\quad(16.8-46.3)\end{array}$ & $\begin{array}{l}24.4 \pm 4.3 \\
\quad(16.3-41.5)\end{array}$ & $0.02 *$ \\
\hline$<18.5$ & 3.6 & 4.8 & 2.7 & 4.6 & 0.01 \\
\hline $18.5-24.9$ & 50.0 & 49.6 & 48.3 & 57.2 & \\
\hline $25.0-29.9$ & 32.2 & 29.4 & 35.4 & 26.1 & \\
\hline$\geq 30$ & 14.2 & 16.2 & 13.6 & 12.1 & \\
\hline \multicolumn{6}{|c|}{ Waist circumference (\%) } \\
\hline Mean \pm SD & $90.0 \pm 13.9$ & $91.6 \pm 15.0$ & $89.9 \pm 13.4$ & $86.9 \pm 12.8$ & $<0.01 *$ \\
\hline Abdominal obesity & 33.6 & 39.7 & 32.2 & 25.1 & $<0.001$ \\
\hline Attention to diet & 67.3 & 49.7 & 74.3 & 81.1 & $<0.001$ \\
\hline
\end{tabular}

$p$ expresses the significance of the differences in the distribution of the subjects in the subgroups between linguistic regions, evaluated by $\chi^{2}$ test (* by ANOVA)

$S D$ standard deviation

Fig. 1 Regional prevalence of obesity and overweight by age group. The prevalence of obesity (black bars) and overweight (gray bars) differs between man and women and tends to increase across age categories

$(15-29=15-29$ years;

$30-44=30-44$ years;

$45-59=45-59$ years;

$>60=60$ years and over).

Differences are also observed between the subjects of the three linguistic regions ( $F$ French,

$G$ German and $I$ Italian), for some age groups

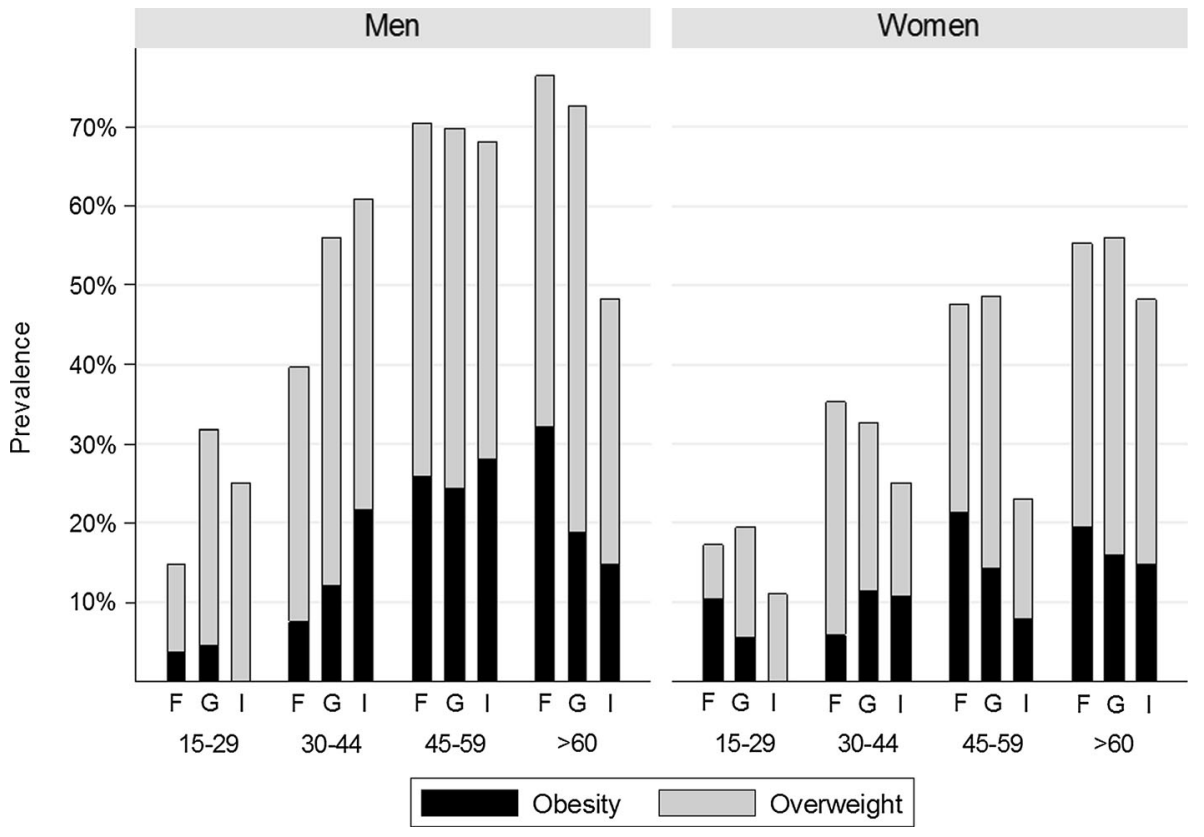



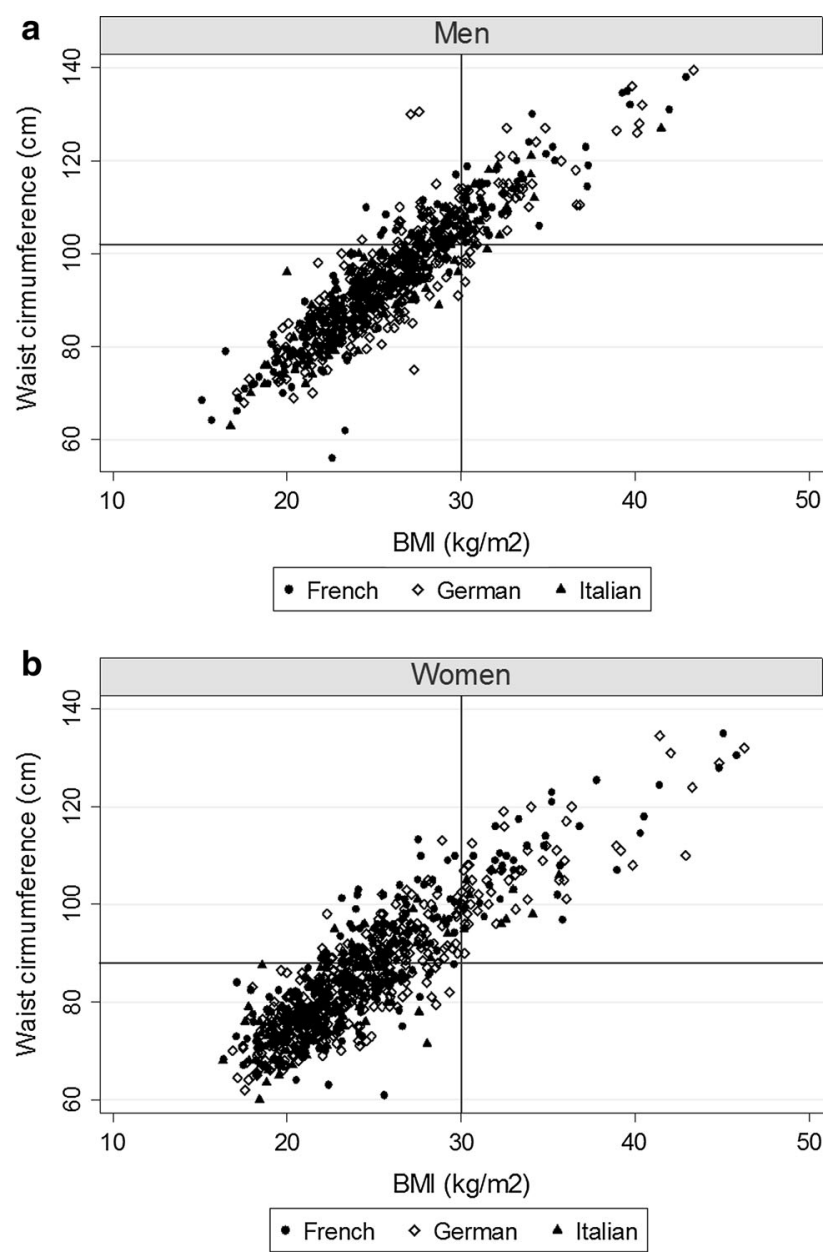

Fig. 2 a, b Comparison of BMI and waist circumference to define obesity. Despite a strong association between waist circumference and BMI in both men and women $(p<0.001$ in linear regression, after adjustment for age and linguistic region), the two criteria identify two slightly different populations. An higher proportion of subjects is classified as obese relying on the waist circumference criterion than based on BMI: $25.2 \%$ of women and $14.1 \%$ of men had an increased waist circumference and normal BMI (left upper quadrant of each graphic)

$176 \pm 7 \mathrm{~cm}$ in men (mean $\pm \mathrm{SD}$ ) and $165 \pm 7 \mathrm{~cm}$ in women, without significant regional differences.

The overall prevalence of overweight and obesity was 32.2 and $14.2 \%$, respectively. In men, $16.6 \%$ of participants were obese and $39.3 \%$ overweighed; in women, the prevalence was $12.0 \%$ for obesity and $25.5 \%$ for overweight.

Obesity prevalence was similar across the three linguistic regions (16.2 \% in French-, $13.6 \%$ in German- and $12.1 \%$ in Italian-speaking Switzerland, $p=0.26$ by ANOVA), unlike overweight prevalence, which significantly differed in unadjusted analyses $(29.4,35.4$ and $26.1 \%$, respectively, $p=0.01$ by ANOVA), being lower in the Italian-speaking population than in the Germanspeaking (Table 1; Fig. 1).
The overall prevalence of abdominal obesity was $33.6 \%$, more than twice as high as the prevalence of obesity defined by BMI (14.2\%). The WC was $95.1 \pm 13.2 \mathrm{~cm}$ in men (mean $\pm \mathrm{SD}$ ) and $85.3 \pm 12.8 \mathrm{~cm}$ in women, with a lower prevalence of abdominal obesity in men $(29.8 \%)$ than in women $(37.2 \%, p<0.01)$, in contrast to the distribution of overweight and obesity.

Significant differences were observed in the regional distribution of abdominal obesity, with the highest prevalence in the French-speaking subjects (39.7\%), an intermediate prevalence in the German-speaking population $(32.2 \%)$ and the lowest in the Italian-speaking region $(25.1 \%, p<0.001)$.

Waist circumference (WC) was positively associated with BMI in both men (correlation coefficient, $r=0.898$, $p<0.001)$ and women $(r=0.882, p<0.001)$. Among men, $14.1 \%$ of the subjects had a BMI $<30 \mathrm{~kg} / \mathrm{m}^{2}$ and an increased WC; this proportion was $25.2 \%$ among women (Fig. 2).

Factors associated with overweight and obesity

As noticeable in Fig. 1, the prevalence of overweight and obesity was higher in older than in younger age group and in men than in women.

In a multiple logistic regressions adjusting for several socio-demographic and behavioral factors, overweight, obesity and abdominal obesity were associated with age and sex (Table 2). In contrast to obesity, the prevalence of abdominal obesity was higher in women than in men.

Being born outside of Switzerland was associated with a higher odds of overweight, obesity and abdominal obesity than being born in Switzerland, and the participants with higher educational level tended to have a lower likelihood of obesity.

Behavioral factors were also significantly associated with the prevalence of obesity: current smokers showed 60-90\% increased odds of being obese, and practicing a physical activity at least once per week was associated with a lower risk of overweight, obesity and abdominal obesity.

Regarding the three linguistic regions of Switzerland, a clear association between the region and the abdominal obesity was found. Italian-speaking subjects had half the odds of abdominal obesity when compared with Frenchspeaking subjects, and participants from the Germanspeaking region had an intermediate risk. No difference was found regarding obesity, and only a trend toward a lower risk of BMI $\geq 25 \mathrm{~kg} / \mathrm{m}^{2}$ was observed in the Italianspeaking region. When sex, age, country of birth, education level, smoking and physical activity were entered in a multiple linear regression model, living in the Italian region remained significantly associated with a lower BMI [beta coefficient (SE): $-0.79(0.35), p=0.02$ compared to 
Table 2 Multivariate analysis of selected factors associated with overweight, obesity and abdominal obesity

\begin{tabular}{|c|c|c|c|c|c|c|}
\hline & \multicolumn{2}{|c|}{ Overweight or obesity } & \multicolumn{2}{|l|}{ Obesity } & \multicolumn{2}{|l|}{ Abdominal obesity } \\
\hline & OR $(95 \% \mathrm{CI})$ & $p$ & OR $(95 \% \mathrm{CI})$ & $p$ & OR $(95 \% \mathrm{CI})$ & $p$ \\
\hline \multicolumn{7}{|l|}{ Sex } \\
\hline Men & 1 (ref.) & & 1 (ref.) & & 1 (ref.) & \\
\hline Women & $0.46(0.36-0.58)$ & $<0.001$ & $0.69(0.50-0.94)$ & 0.02 & $1.60(1.26-2.04)$ & $<0.001$ \\
\hline \multicolumn{7}{|l|}{ Linguistic region } \\
\hline French & 1 (ref.) & & 1 (ref.) & & 1 (ref.) & \\
\hline German & $1.23(0.96-1.59)$ & 0.10 & $0.84(0.60-1.17)$ & 0.31 & $0.72(0.55-0.93)$ & 0.01 \\
\hline Italian & $0.75(0.52-1.08)$ & 0.13 & $0.79(0.48-1.31)$ & 0.37 & $0.51(0.34-0.76)$ & 0.001 \\
\hline \multicolumn{7}{|l|}{ Age group (years) } \\
\hline $15-29$ & 1 (ref.) & & 1 (ref.) & & 1 (ref.) & \\
\hline $30-44$ & $2.66(1.86-3.79)$ & $<0.001$ & $2.32(1.23-4.35)$ & $<0.01$ & $2.81(1.84-4.30)$ & $<0.001$ \\
\hline $45-59$ & $4.72(3.34-6.66)]$ & $<0.001$ & $4.57(2.56-8.14)$ & $<0.001$ & $4.63(3.08-6.96)$ & $<0.001$ \\
\hline$\geq 60$ & $5.97(4.26-8.36)$ & $<0.001$ & $4.28(2.43-7.56)$ & $<0.001$ & $9.06(6.10-13.47)$ & $<0.001$ \\
\hline \multicolumn{7}{|l|}{ Education level } \\
\hline Primary & 1 (ref.) & & 1 (ref.) & & 1 (ref.) & \\
\hline Secondary & $1.05(0.75-1.47)$ & 0.76 & $0.88(0.57-1.36)$ & 0.57 & $1.04(0.73-1.48)$ & 0.84 \\
\hline Tertiary & $0.72(0.51-1.02)$ & 0.06 & $0.60(0.38-0.94)$ & 0.03 & $0.76(0.53-1.09)$ & 0.13 \\
\hline \multicolumn{7}{|l|}{ Country of birth } \\
\hline Switzerland & 1 (ref.) & & 1 (ref.) & & 1 (ref.) & \\
\hline Other & $1.41(1.07-1.86)$ & 0.014 & $1.53(1.07-2.17)$ & 0.02 & $1.89(1.43-2.52)$ & $<0.001$ \\
\hline \multicolumn{7}{|l|}{ Smoking status } \\
\hline Never or former & 1 (ref.) & & 1 (ref.) & & 1 (ref.) & \\
\hline Current & $1.63(1.26-2.10)$ & $<0.001$ & $1.91(1.39-2.62)$ & $<0.001$ & $1.61(1.25-2.09)$ & $<0.001$ \\
\hline \multicolumn{7}{|c|}{ Leisure-time physical activity } \\
\hline$\leq 1 \times /$ week & 1 (ref.) & & 1 (ref.) & & 1 (ref.) & \\
\hline$>1 \times /$ week & $0.78(0.62-0.98)$ & 0.03 & $0.64(0.47-0.88)$ & $<0.01$ & $0.71(0.56-0.90)$ & $<0.01$ \\
\hline
\end{tabular}

Results are expressed as odds ratio and (95\% CI)

Statistical analysis by multiple logistic regression with the reported covariates

ref. reference category

French-speaking subjects]; no difference was found between French- and German-speaking subjects ( $p=0.81$ ). WC was lower in the Italian-speaking region than in the French-speaking region [beta coefficient (SE): -4.03 (0.97), $p<0.001]$. We found similar associations of socio-demographic and behavioral factors with overweight, obesity or abdominal obesity across linguistic regions (all $p$ for interactions $>0.01$ ).

\section{Nutritional factors}

Overall, $67.3 \%$ of participants reported to pay attention to their diet. In multiple logistic regression analysis, women were more likely than men to report paying attention to diet [OR 2.00 (SE 0.24), $p<0.001]$. Participants living in the Italian- [OR 4.62 (SE 0.94), $p<0.001$ ] and in the Germanspeaking region [OR 3.03 (SE 0.38), $p<0.001$ ] reported a greater attention to diet than people of the French-speaking region. Among age categories, only the older subjects ( $\geq 65$ years) presented a significant difference in the reported attention to diet [OR 1.74 (SE 0.28), $p=0.001]$. There was no association with the educational level, nor with the country of birth of the participants.

Obese had higher estimated salt intake (13.3 \pm 4.3 $\mathrm{g} / 24 \mathrm{~h}$ in men and $10.1 \pm 3.7 \mathrm{~g} / 24 \mathrm{~h}$ in women) than overweight $(10.8 \pm 3.4$ and $8.4 \pm 2.7)$ and normal weight subjects $(9.4 \pm 3.2$ and $7.1 \pm 2.6 \mathrm{~g} / 24 \mathrm{~h}$, respectively), after correction for age, linguistic region, birthplace, education level, smoking and physical activity (Fig. 3). The trend across BMI categories was significant by the nonparametric test by Cuzick $(p<0.001$ in both men and women). Similarly, estimated potassium and protein intake increased across BMI categories in both men and women with a $p<0.001$ for trend, and the urinary $\mathrm{Na}-\mathrm{K}$ ratio increased significantly ( $p$ for trend 0.001 in men and $<0.01$ in women) (Fig. 3). 

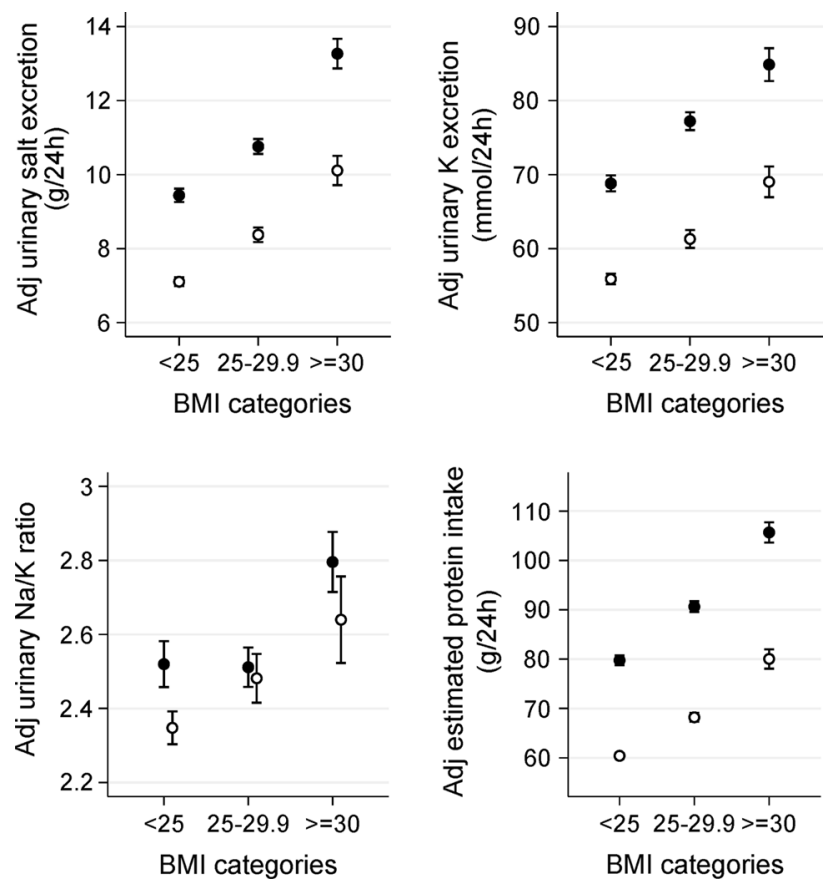

Fig. 3 Adjusted urinary $\mathrm{Na}$ and $\mathrm{K}$ excretion, $\mathrm{Na} / \mathrm{K}$ ratio and estimated protein intake by BMI categories. Estimated salt, potassium and protein intake increased across BMI categories (normal weight: BMI $<25 \mathrm{~kg} / \mathrm{m}^{2}$; overweight: BMI $25-30 \mathrm{~kg} / \mathrm{m}^{2}$; obese: BMI $\geq 30 \mathrm{~kg} / \mathrm{m}^{2}$ ) in both men (black dots) and women (white dots). $p<0.001$ by likelihood ratio test with two degrees of freedom. The positive trend of urinary $\mathrm{Na}-\mathrm{K}$ ratio across $\mathrm{BMI}$ categories indicated a less favorable nutrition profile in obese than in lean subjects $(p=0.015)$

The urinary $\mathrm{Na} / \mathrm{K}$ ratio was associated positively with BMI only in the French- and German-speaking regions, but not in the Italian-speaking region ( $p$ of the interaction $=0.002$ for a likelihood ratio test with two degrees of freedom).

\section{Discussion}

In epidemiological surveys, obesity may be defined based on body mass index (BMI) [7] or by using waist circumference (WC) [21]. Both measures are associated with increased morbidity and mortality [1], although they may identify slightly different populations. When BMI is used as benchmark, overweight and obesity affect nearly half of the Swiss adolescents and adults, with $16.6 \%$ of men and $12.0 \%$ of women being obese and 39.3 and $25.5 \%$, respectively, overweight.

Comparing our results on measured height and weight with former (self-reported) data from the Swiss Health Survey 2007 [9, 22], we found a significant higher mean body weight in our population in both men and women, whereas mean reported body height did not differ between the two surveys (data not shown). The underestimation of self-reported anthropometric variables [10, 11] could at least partially explain the great progression in the prevalence of obesity (from $8.2 \%$ in SHS 2007 to $14.2 \%$ in this survey) and overweight (from 29.1 to $32.2 \%$ ) observed in the Swiss population over 3 years.

The latest Swiss studies measuring anthropometric parameters-CoLaus [23] in 2003-2006 and National Blood Pressure Week (NBPW) [24] in 2009-were performed on selected samples-a single town in CoLaus and a sample of subjects in NBPW attending the participating pharmacies on spontaneous run-in basis - thus do not allow any comparison between the different linguistic-cultural regions of Switzerland.

Only one study performed in 1977 measured BMI of people from the three Swiss linguistic regions [25].

Using WC to assess obesity resulted in a higher abdominal obesity prevalence of $33.6 \%$, with a larger proportion of women than men presenting an abdominal obesity. This difference between the two methods relies on the fact that up to $25.2 \%$ of the women had a normal or slightly elevated BMI and an increased WC, being thus classified as obese on the WC criterion but not by the BMI criterion.

Older age was associated with higher prevalence of overweight, obesity and abdominal obesity in both men and women. Among socioeconomic and behavioral factor, a low educational level, current smoking, scarce physical activity and being migrant were associated with an higher prevalence of obesity, as reported in previous studies [26-28].

When comparing the three linguistic regions, we found a similar prevalence of obesity, but a significant difference in overweight and abdominal obesity, with subjects from the Italian-speaking Switzerland having the lowest prevalence (26.1\% for overweight and $25.1 \%$ for abdominal obesity). These results are in line with the heterogeneous distribution of obesity in European countries, with prevalence ranging from $16.9 \%$ in France (on year 2007) to $9.8 \%$ in Italy (on 2005) [8]. This heterogeneity could be related to different eating habits in relation to cultural factors or food availability, depend on different education and socio-economic conditions or be the consequence of different national policy strategies, regarding diet, transport facilities and awareness of the health risks [26, 29]. In our survey, a difference between linguistic areas was observed, despite a common socio-economic and governmental framework. This difference persisted after adjustment for demographic factors (sex, age and country of birth), education level and the reported amount of physical activity during leisure time, suggesting the presence of dietary factors which may contribute to the observed regional difference. This hypothesis finds further support in the results of the 
reported attention paid to alimentation, significantly greater in women than in men, and in participants from the Italianspeaking part. Similar results with analogous regional differences were observed in the previous Swiss Health Surveys of 1992-2007 [22].

Urinary salt excretion over $24 \mathrm{~h}$, which represents a good surrogate of the dietary salt intake [30], was significantly higher in overweight and obese people as compared to normal weight people. Similarly, the estimated protein and potassium intakes were associated positively with BMI categories and were higher in men than in women. Looking at the urinary sodium-to-potassium ratio in our population, we found higher values in obese than in normal weight subjects, suggesting a less favorable food profile in obese, than in lean peoples. In fact, urinary $\mathrm{Na}-\mathrm{K}$ ratio has been previously used as marker of the quality of nutrition [20], exploiting the observation that sodium derives principally from processed food, confectioneries, bread and "junk food," while fruit and vegetables are the major contributors to the dietary potassium $[19,20]$. High urinary sodium and low urinary potassium have also been linked to several chronic illnesses, such as hypertension and cardiovascular disease [31, 32].

Previous studies also found obesity or the metabolic syndrome to be associated with higher salt intake [19, 33]. Increased salt intake in obese patients may simply result from increased food consumption, promoted by several mechanisms, such as reduced satiety signals [34, 35]. The link between obesity and salt consumption may, however, be more intricate than usually considered. There is in fact some evidence arguing that obesity may lead to increased water and salt consumption due to an upregulation of the renin-angiotensin-aldosterone system (RAAS) [36-38]. Some have even postulated that increased salt consumption may lead to obesity by stimulating the consumption of soft drinks and fructose, establishing a vicious circle [14]. According to a recently published hypothesis ("The Salted Food Addiction Hypothesis"), salt intake and calories consumption could both act as opiate agonists in the brain's pleasure center $[15,16]$. Independent of the questionable causative role of salt in the development of obesity, salt consumption has been associated with hypertension, with a stronger link in obese people, who seem to develop a saltsensitive hypertension, which can be reversed by body weight reduction $[39,40]$. Salt restriction should therefore be an integral part of the dietary and lifestyle management of obese patients.

These results should be interpreted in the light of the study's strengths and limitations. Since 35 years, this is the first population-based study comparing measured BMI in the three linguistic regions of Switzerland. The fact that sodium, potassium and urea excretions were measured in 24-h urine in a large sample of the Swiss population is an important strength of this study, permitting to evaluate objective biomarkers related to nutrition, thereby avoiding reporting biases. Evaluation of dietary intake is indeed often based on self-report dietary assessment instruments, because of either a lack of other more objective measures of dietary intake or because of lower costs, a modality leading to bias and inaccuracy in the studied data [41].

The main limitation of our study is the low overall participation rate of $10 \%$. We explain this low participation rate by the unattractiveness of 24-h urine collection, together with the two-stage sampling strategy, which implies that the person we contacted by phone was not automatically the one selected to enter the study. Furthermore, the necessity to conduct limited convenience sampling to recruit young and middle-aged people may have biased the results on these population strata, recruiting subjects with a greater awareness on health issues.

In conclusion, our data confirm that obesity and overweight are common in Switzerland, affecting almost half of the Swiss resident population aged $>15$ years.

Similar to what was found in prior studies [23, 24], using BMI and WC to define obesity led to different prevalence's, with a larger proportion of women identified as obese when using WC. The positive association between dietary salt intake and BMI deserves more attention, not only because of the known link between salt and hypertension in obese, which may contribute to the increased morbidity attributed to higher BMI, but also in the framework of a possible role of salt consumption in the development of obesity. Attention to salt intake, to the quality of the consumed food as well as to the amount of food ingested should be increased, in order to better control their cardiovascular risk profile. At national public health level, preventive strategies targeting obesity should be tailored considering the differences in the population identified by the different definitions of obesity. In the meantime, measures targeting a decrease in the salt consumption, e.g., by lowering the salt in processed foods, could not only have a favorable effect on hypertension, but may influence positively the trend toward an increasing prevalence of obesity in the Swiss population as in other high-income countries.

Acknowledgments We thank all study participants as well as study nurses and assistants in each center, who made this study possible. The study was funded mainly by the Swiss Federal Office of Public Health (Contracts Nos. 09.004165/404.0101/-2 and 09.005791/ 414.0000/-74). A contribution by the Swiss Society of Hypertension had also been received. The Nephrology Division and the Institute of Social and Preventive Medicine of Lausanne University Hospital provided further logistic and analytical support. MBO is supported by the Swiss School of Public Health Plus.

Conflict of interest On behalf of all authors, the corresponding author states that there is no conflict of interest. 


\section{References}

1. Pischon T, Boeing H, Hoffmann K, Bergmann M, Schulze MB, Overvad K, van der Schouw YT, Spencer E, Moons KG, Tjonneland A et al (2008) General and abdominal adiposity and risk of death in Europe. N Engl J Med 359:2105-2120

2. Whitlock G, Lewington S, Sherliker P, Clarke R, Emberson J, Halsey J, Qizilbash N, Collins R, Peto R (2009) Body-mass index and cause-specific mortality in 900,000 adults: collaborative analyses of 57 prospective studies. Lancet 373:1083-1096

3. Murphy NF, MacIntyre K, Stewart S, Hart CL, Hole D, McMurray JJ (2006) Long-term cardiovascular consequences of obesity: 20-year follow-up of more than 15,000 middle-aged men and women (the Renfrew-Paisley study). Eur Heart J 27:96-106

4. Yusuf S, Hawken S, Ounpuu S, Bautista L, Franzosi MG, Commerford P, Lang CC, Rumboldt Z, Onen CL, Lisheng L et al (2005) Obesity and the risk of myocardial infarction in 27,000 participants from 52 countries: a case-control study. Lancet 366:1640-1649

5. Romero-Corral A, Montori VM, Somers VK, Korinek J, Thomas RJ, Allison TG, Mookadam F, Lopez-Jimenez F (2006) Association of bodyweight with total mortality and with cardiovascular events in coronary artery disease: a systematic review of cohort studies. Lancet 368:666-678

6. Finucane MM, Stevens GA, Cowan MJ, Danaei G, Lin JK, Paciorek CJ, Singh GM, Gutierrez HR, Lu Y, Bahalim AN et al (2011) National, regional, and global trends in body-mass index since 1980: systematic analysis of health examination surveys and epidemiological studies with 960 country-years and 9.1 million participants. Lancet 377:557-567

7. World Health Organisation (WHO) (2013) Overweight and obesity, Factsheet N311. http://www.who.int/mediacentre/fact sheets/fs 311 . Accessed 29 July 2013

8. World Health Organisation (WHO) (2013) Global database on body mass index. http://www.who.int/bmi. Accessed 29 July 2013

9. Eichholzer M, Bovey F, Jordan P, Schmid M, Stoffel-Kurt N (2010) Daten rund um das Thema Körpergewicht: Schweizerische Gesundheitsbefragung 2007. Praxis 99:895-906

10. Taylor AW, Dal Grande E, Gill TK, Chittleborough CR, Wilson DH, Adams RJ, Grant JF, Phillips P, Appleton S, Ruffin RE (2006) How valid are self-reported height and weight? A comparison between CATI self-report and clinic measurements using a large cohort study. Aust N Z J Public Health 30:238-246

11. Gorber SC, Tremblay M, Moher D, Gorber B (2007) A comparison of direct vs. self-report measures for assessing height, weight and body mass index: a systematic review. Obes Rev $8: 307-326$

12. Faeh D, Marques-Vidal P, Chiolero A, Bopp M (2008) Obesity in Switzerland: do estimates depend on how body mass index has been assessed? Swiss Med Wkly 138:204-210

13. Binder RK, Barth J, Schmid JP, Saner H (2011) Burden of abdominal obesity in cardiac rehabilitation patients: Results from the Swiss CaRe study. Swiss Med Wkly 141:w13153

14. He FJ, Marrero NM, MacGregor GA (2008) Salt intake is related to soft drink consumption in children and adolescents: a link to obesity? Hypertension 51:629-634

15. Cocores JA, Gold MS (2009) The salted food addiction hypothesis may explain overeating and the obesity epidemic. Med Hypotheses 73:892-899

16. Blum K, Oscar-Berman M, Barh D, Giordano J, Gold M. (2013) Dopamine genetics and function in food and substance abuse. J Genet Syndr Gene Ther 4. doi:10.4172/2157-7412.1000121

17. Grundy SM, Cleeman JI, Daniels SR, Donato KA, Eckel RH, Franklin BA, Gordon DJ, Krauss RM, Savage PJ, Smith SC Jr et al (2005) Diagnosis and management of the metabolic syndrome: an American Heart Association/National Heart, Lung, and Blood Institute Scientific Statement. Circulation 112:2735-2752

18. Maroni BJ, Steinman TI, Mitch WE (1985) A method for estimating nitrogen intake of patients with chronic renal failure. Kidney Int 27:58-65

19. Beer-Borst S, Costanza MC, Pechere-Bertschi A, Morabia A (2009) Twelve-year trends and correlates of dietary salt intakes for the general adult population of Geneva, Switzerland. Eur J Clin Nutr 63:155-164

20. Murakami K, Sasaki S, Takahashi Y, Uenishi K (2010) Neighbourhood food store availability in relation to $24 \mathrm{~h}$ urinary sodium and potassium excretion in young Japanese women. Br J Nutr 104:1043-1050

21. World Health Organisation (WHO) (2008) Waist circumference and waist-hip ratio: report of a WHO expert consultation. WHO Library, Geneva

22. Eichholzer M, Bovey F, Jordan P, Probst-Hensch N, Stoffel-Kurt N (2010) Data on overweight and nutrition in the 2007 Swiss Health Survey. Praxis 99:17-25

23. Marques-Vidal P, Bochud M, Mooser V, Paccaud F, Waeber G, Vollenweider P (2008) Prevalence of obesity and abdominal obesity in the Lausanne population. BMC Public Health 8:330

24. Volken T, Schaffert R, Ruesch P (2009) Need for weight management in Switzerland: findings from National Blood Pressure Week 2009. BMC Public Health 11:473

25. Gutzwiller F, Nater B, Martin J (1985) Community-based primary prevention of cardiovascular disease in Switzerland: methods and results of the National Research Program (NRP 1A). Prev Med 14:482-491

26. Finkelstein EA, Ruhm CJ, Kosa KM (2005) Economic causes and consequences of obesity. Annu Rev Public Health 26:239-257

27. Rabin BA, Boehmer TK, Brownson RC (2007) Cross-national comparison of environmental and policy correlates of obesity in Europe. Eur J Public Health 17:53-61

28. Marques-Vidal P, Vollenweider P, Waeber G, Paccaud F (2011) Prevalence of overweight and obesity among migrants in Switzerland: association with country of origin. Public Health Nutr 14:1148-1156

29. Spence JC, Cutumisu N, Edwards J, Raine KD, Smoyer-Tomic K (2009) Relation between local food environments and obesity among adults. BMC Public Health 9:192

30. Schachter J, Harper PH, Radin ME, Caggiula AW, McDonald RH, Diven WF (1980) Comparison of sodium and potassium intake with excretion. Hypertension 2:695-699

31. Appel LJ, Brands MW, Daniels SR, Karanja N, Elmer PJ, Sacks FM (2006) Dietary approaches to prevent and treat hypertension: a scientific statement from the American Heart Association. Hypertension 47:296-308

32. Srinath RK, Katan MB (2004) Diet, nutrition and the prevention of hypertension and cardiovascular diseases. Public Health Nutr 7:167-186

33. Hoffmann IS, Cubeddu LX (2009) Salt and the metabolic syndrome. Nutr Metab Cardiovasc Dis 19:123-128

34. Geliebter A, Gluck ME, Hashim SA (2005) Plasma ghrelin concentrations are lower in binge-eating disorder. J Nutr 135: $1326-1330$

35. Hellstrom PM, Geliebter A, Naslund E, Schmidt PT, Yahav EK, Hashim SA, Yeomans MR (2004) Peripheral and central signals in the control of eating in normal, obese and binge-eating human subjects. Br J Nutr 92:S47-S57

36. Boustany CM, Bharadwaj K, Daugherty A, Brown DR, Randall DC, Cassis LA (2004) Activation of the systemic and adipose reninangiotensin system in rats with diet-induced obesity and hypertension. Am J Physiol Regul Integr Comp Physiol 287:R943-R949 
37. Marzolla V, Armani A, Zennaro MC, Cinti F, Mammi C, Fabbri A, Rosano GM, Caprio M (2012) The role of the mineralocorticoid receptor in adipocyte biology and fat metabolism. Mol Cell Endocrinol 350:281-288

38. Nagase M, Fujita T (2009) Mineralocorticoid receptor activation in obesity hypertension. Hypertens Res 32:649-657

39. Dumler F (2009) Dietary sodium intake and arterial blood pressure. J Ren Nutr 19:57-60

40. Hoffmann IS, Alfieri AB, Cubeddu LX (2008) Salt-resistant and salt-sensitive phenotypes determine the sensitivity of blood pressure to weight loss in overweight/obese patients. J Clin Hypertens 10:355-361

41. Poslusna K, Ruprich J, de Vries JH, Jakubikova M, van't Veer P (2009) Misreporting of energy and micronutrient intake estimated by food records and 24 hour recalls, control and adjustment methods in practice. Br J Nutr 101:S73-S85 